others?), and god knows I no longer blame the pleasant receptionist who must ask three questions one hundred times a day, while she wants only to return to the rating for sexual attraction in Redbook; or the manager doing his best to rise, someday, he trembles to think, to an enclosed office on mahogany row, his service awards and aged brandy hushed and elegant in the glass cabinet; or the ones who believed TV promises and now sit before terminals, pale green light like a sigh on their faces;

or the guys trading numbers in the mailroom, half joking, half praying for the combination that might land them in the local paper, their arm around a woman with an uncertain smile; or even the strong willed ones who descend each noon from glassy clouds, the ones who've learned to say three things at once without anger and appear kind, showing their even teeth-for some are kind, and not one of them unnatural. My client keeps me waiting. I light a third cigarette, check my watch. The painting on the lobby wall is right before me, calm, easy to look at, so little movement inside it is impossible to describe. I touch

my forehead and my fingers smear a thin line of moisture. The receptionist is waving.

\title{
Looking at a Photograph of my Father at My Age
}

The graying brushcut stands up like a warning:

This black and white face is square, lean and dangerous. Seven years out of the FBI and he 
still wears the SI trenchcoat. Hands in pockets, cigarette in lips, one eye squinting at a curl of smoke. . . The posing is only partialBogart never worked undercover vice in Harlem or chased a racketeer down the frozen streets of Buffalo. The flat cruelty of the mouth is real. As my hunger for the tales was real, sometimes outweighing a reticence trained in by Hoover (whose scary pug face guarded the den wall), and I'd get one bare bones cops and robbers before bed. How much I wanted those shoulders! - Level and wide enough to hold my sister and me, one to a side. He'd do kip-ups, brandys, one arm push-ups between flipping hamburgers on our Levittown lawn, my friends awed into quiet. This was about the time I began to withdraw, amazed to find more love for Kipling than hardball. Mixing my Gilbert chemicals in the attic, stroking a wan guitar. . . . I slip the photograph back under drafts of old work, study my face in the bathroom mirror. Enough resemblence to imagine us as brothers, perhaps - the photograph the one to step in when the reflection caused a fight in some bar. Later, the reflection might compose a little something, a sweet poem, to smooth out the photograph's wife. She'd be touchy, emotional, crisp shadow to his strength. Mum guardian of his weakness.

\section{A Grace}

Let's have no more I remember poems, at least not until the self thaws out and we can move easily in more than one direction. So much lunatic pruning in a dead garden, 